crats, the party of health care reform, are in a precarious political position because of the failures of the previous administration and may not have enough votes to push through any plan after the elections of 2010. But we are talking about an enor- mous and hugely costly program with a profound impact on our economy and, indeed, our entire future. We simply have to get it right if we are to take it on at all.

\section{David G. Nathan}

Dana-Farber Cancer Institute and Children's Hospital, Boston, Massachusetts, USA. E-mail: david_nathan@dfci.harvard.edu.

J. Clin. Invest. 119:2847-2848 (2009). doi:10.1172/JCI40994.

\title{
Healing health care
}

y 2018, health care expenditures are expected to consume more than $20 \%$ of US gross domestic product (1). Over the last decade, there has been a marked increase in health care spending without corresponding improvements in longevity or quality of life. In short, we simply are not getting our money's worth, and we need to improve the value of our health care dollar.

Reduce or eliminate direct-to-consumer advertising. My healthy seven-year-old niece complained that her bones were sore and she needed Boniva (once-monthly oral ibandronate). In the United States, health care advertising is pervasive and has become part of the fabric of everyday life. The most dramatic increases in health care spending have been since 1997, the year the FDA relaxed regulation on direct-to-consumer advertising on television. From 1997 to 2007, direct-to-consumer advertising for prescription drugs increased $330 \%$ (2). In 2005, the budget for prescription drug advertising was $\$ 30$ billion. Notably, this cost estimate does not include advertising for hospitals, insurers, devices, and other health-related services, and it does not include the costs of unnecessary visits and testing. Direct-toconsumer advertising of prescription drugs is having long-term consequences on the pharmaceutical industry, steering business strategy toward "lifestyle" drugs and away from the more difficult-to-treat diseases such as heart disease, cancer, and diabetes. Research is needed to devise new strategies for these disorders, and the budget for research should index to health care expenditures. A redirection of the direct-to-consumer advertising budget toward research would be a better investment in our future. Ironically, an additional \$45-\$60 million has been spent this year on advertising for health care reform (3). The winners are clearly the advertising companies, and the losers are those who have to explain to their children what erectile dysfunction is and why drugs are so expensive.

Toss out exclusions for preexisting conditions. Insurance providers would like to screen and exclude those who are ill and those who are at risk of becoming ill, since providing for the healthy is a better business strategy. I am a geneticist, and we now routinely use genetic diagnoses to guide clinical management and predict risk for future disease. Advances in human genetics are obliterating the concept of the preexisting condition, since all human disease has a heritable component. The ability to predict risk for disease is advancing at light speed. Such genetic research can nearly instantaneously be converted to clinical testing, where it usefully predicts risk of disease, the insurers' dream come true. The Genetic Information Nondiscrimination Act (GINA) took a first step toward protecting against insurance discrimination based on genotype (4). Treating a genetic condition is not protected under GINA. There is an increasingly blurry line between an "at-risk" genotype versus early-phase disease that requires therapy to reduce risk. The greatest advances of this decade are deriving from the fruits of the human genome project. Curiously, coverage for genetic testing is still limited, and earlyphase risk reduction therapy is not always covered. Eliminating an insurer's ability to void coverage of a preexisting condition has been extensively discussed in the context of health care reform. The insurance industry is politically mighty; it is up to the public to keep pressure on members of Congress to legislate protection against the preexisting condition exclusion.

Bring bealth information management into the modern era. One of the biggest money pits for our health care dollars is the outdated management of health information. The electronic information age arrived some time ago but left health information behind. Health information is stored in a variety of formats that are often incompatible, ranging from paper to obsolete electronic media. Health care providers do not share information readily with each other. Sharing information is time consuming and a largely uncompensated activity. It is far easier to reorder a test than to request the results from the test that has already been performed. A uniform format for health care information should be established and used. Information management and maintenance should be taken from the control of the health providers and given to organizations with expertise in information management. Patients should control who has access to their personal health information. It should be within a patient's right to authorize or deauthorize access to health information. Patients should be able to readily determine who has accessed their heath information and for what purpose. Health care providers should not "own" patients' health information. Diagnostic testing increasingly relies on imaging, and while I can watch just about anything on YouTube, I frequently cannot view my patients' echocardiograms performed at outside institutions. Having a uniform format would allow ready access and viewing, which would result in better health care, improved quality control, and a reduction in unnecessary testing. It is time for health care information to grow up and at least be as good as iTunes. Health care providers have repeatedly demonstrated an inadequacy in this area, and it seems a striking opportunity for the business community to design and implement a new approach to this problem.

\section{Elizabeth M. McNally}

The University of Chicago, Chicago, Illinois, USA.E-mail: emcnally@uchicago.edu.

J. Clin. Invest. 119:2848 (2009). doi:10.1172/ JCI41037.

1. Centers for Medicare and Medicaid Services. National health expenditure data overview. http:// www.cms.hhs.gov/nationalhealthexpenddata/ 01_overview.asp.

2. Donohue, J.M., Cevasco, M., and Rosenthal, M.B. 2007. A decade of direct-to-consumer advertising of prescription drugs. N. Engl. J. Med. 357:673-681.

3. Campaign Media Analysis Group. http://www. tnsmi-cmag.com/index.asp.

4. Anonymous. 2008. Genetic Information Nondiscrimination Act. HR 493. 110th Congress, 2nd sess. Congr. Rec. (Dly. Ed.). 154:D661. 